\title{
DEL PASADO A LA HISTORIA ${ }^{1}$
}

\author{
Antonio GOMEZ RAMOS \\ Universidad Carlos III
}

\begin{abstract}
El auténtico historiador tiene que tener la fuerza de transformar lo que todos conocen en algo inaudito ${ }^{2}$.
\end{abstract}

(NIETZSCHE)

Mientras no hayamos cambiado el mundo, la historia no podrá ensenarnos nada.

(Heiner MULLER)

\section{Aproximación al turista con conciencia histórica}

El turista que, a finales de este siglo, callejea por ciudades ennoblecidas como "patrimonio histórico", se detiene disciplinadamente ante cualquier construcción, sea un palacio, un templo o un puente, que parezca justificar ese título. Si no va provisto de su oportuna gúa, una placa relata en cuatro o cinco líneas la historia del monumento; y en ningún caso, ni siquiera en el pueblo más deprimido, falta ya una suerte de etiqueta con la fecha de construcción: siglo $\mathrm{XIV}$, siglo XVIII, siglos $\mathrm{X}$ al XII... El primer efecto de la etiqueta puede ser recordarle al que lo contempla "desde cuándo" esta ahl eso que contempla - como una advertencia de su caducidad y de la inmensidad de la historia-. Pero el turista posee una cierta cultura general, y se repone apresurándose a identificar

1 Durante la redacción de este ensayo, el autor disfrutó de una ayuda postdoctoral de la Fundación Caja de Madrid.

2 Vom Nutzen und Nachteil der Historie für das Leben KSA, I, 294. 
el XVIII con las pelucas ilustradas, el XII con las Cruzadas o las tinieblas medievales, el II con los romanos. Un esquema de la historia universal le permite situar las piedras que contempla en la casilla adecuada: Barroco, Edad Media, Edad Antigua; asociadas con estilos artísticos y acontecimientos políticos, sociales o culturales coetáneos. Por lo demás, es consciente, con una mezcla de orgullo e ironía, de que la etiqueta fue adherida mucho después de la construcción y de una probable restauración, en su propia época, quizá unos días antes de que él haya llegado al sitio en cuestión. Por eso, cuando se trata de algo más reciente, de este siglo, en que estilos, modas o mentalidades pierden los contornos más claros, comprende que no haya placas, pero es capaz de realizar mentalmente una asignación temporal, más exacta en el espacio cronológico, si bien, frente a la anterior solidez del singular —usiglo $\mathrm{X} »$ - difuminada en un impreciso plural: «los años veinte», «años treinta»..., como si las casillas estuvieran aun abiertas, no ensambladas del todo.

En todo caso, nuestro turista, oportunamente dotado de conciencia histórica, parece disponer de una cartografia previa en la que el "puzzle» del tiempo queda articulado y el patrimonio histórico recogido: la Historia contabilizada como "patrimonio", esto es, fortuna, legado, o posesión. Los cuadrantes con los que se traza esa cartografía son las épocas o períodos históricos. Con ellos, el hombre -el hombre que los utiliza, que es el hombre de un periodo histórico concreto- parece situarse en el tiempo, contarlo, valorarlo. Desde ahí puede conocer el pasado, puede venerarlo como un anticuario, puede desearlo, hasta suspirar por la época en que le gustaría haber vivido ${ }^{3}$. Además, su conciencia histórica puede ser tan aguda como para no ignorar que todos esos restos del pasado que contempla, que admira, que, reconoce, le determinan en lo que él es, testimonian también, silenciosamente, de infinitas posibilidades masacradas y perdidas, de la sangre de las víctimas y del sufrimiento de los oprimidos. Por último, teniendo presente a Benjamin, puede venerar el pasado sin olvidar que uno hay nunca un documento de la cultura que no lo sea, a la par, de la barbarie" ${ }^{4}$.

3 Sobre las posibles actitudes respecto al pasado del hombre moderno, resulta muy ilustrativo LOWENTHAL, The Past is a Foreign Country, CUP, Cambridge, 1995. Especialmente, la primera parte.

4 Uber den Begriff der Geschichte, en Sprache und Geschichte, Reklam, Stuttgart, 1992. pág. 145. Se halla en la séptima tesis sobre filosofla de la historia. Por lo demás, dicho sea de paso, esta cita se halla grabada en el hermoso monumento, también funerario, que recuerda a Walter Benjamin en Port-Bou, su lugar de fallecimiento. 


\section{El contrapeso de la historia}

Nunca ha sabido el ser humano tanto del pasado, ni ha preservado sus restos con tanta veneración, como ocurre en este final de siglo, de modo que sería abusar de la vocación crítica de la filosofía, sobre todo de la filosofía que reconoce el valor de lo histórico, buscarle tres pies a esta halagüeña situación. Pero sí cabe hacerse cargo de que esta actitud del turista con conciencia histórica representa una cierta concepción dominante de la historia y la historicidad en nuestros días; $y$, como tal, merece ser examinada. Hay, además, una teoría, al menos, que intenta explicarla ${ }^{5}$ y que podría ser, en cierto modo, la conciencia filosófica del turista. Parte de una paradoja: esta época de nuestro turista, que ha destruido tanto del pasado y ha roto más radicalmente que ninguna con la tradición anterior, rescata y preserva también más de lo que ha hecho ninguna otra: en museos, en archivos, en la conservación de ruinas o la restauración de monumentos, en parques naturales (que, a su vez, hacen de la naturaleza un "pasado" conservado), en el acopio de saber histórico y la recuperación de "tradiciones populares». Ello ocurre por la sencilla razón de que la modernización y el consiguiente desencantamiento del mundo habrian producido un creciente extrañamiento del hombre respecto a aquél; desarraigado entre los nuevos procesos técnicos que le dominan, el ciudadano moderno experimenta el desgarro entre el pasado del que proviene y lo que está por venir, entre las experiencias anteriores y sus inciertas expectativas. Artificialización y desnaturalización aceleradas, reificación y deshistorización definen la Modernidad. Sólo que ésta, por un sabio mecanismo compensatorio propio de un ser inercial como es el humano, desarrolla los procesos oportunos para mantener el equilibrio: sentido de la naturaleza y sentido de la historia, con las actividades conservadoras mencionadas más arriba. La modernidad se hace soportable cuando las pérdidas experimentadas en el mundo de la vida se ven compensadas por la riqueza de una tradición que retorna como familiar lo que se había vuelto extraño. De modo que el turista, profesional urbano inmerso en el vertiginoso desarrollo tecnológico, ve salvada su humanidad en la compensación que le ofrece el monumento antiguo, la piedra preservada. Las regiones y sociedades más exitosas suelen preciarse, publicitariamente, de conjugar "tradición y

5 La célebre teoría de la compensación, que argumenta la necesidad moderna de las ciencias del espíritu. La exponemos aqul, condensadamente, según MARQUARD, "Zeitalter der Weltfremdheit? Beitrag zur Analyse der Gegenwartw, y "Uber die Unvermeidlichkeit der Geisteswissenschaften", en Apologie des Zufalligenw, Reklam, Stuttgart, 1986. 
modernidad". El peso y la solidez del pasado, en el que el turista se reconoce porque sabe que viene de él, le permite mantener la cabeza en el descentrado y evanescente mundo moderno. "Llevar tanto del pasado al porvenir como sea posible" ${ }^{6}$ es la consigna.

A modo de corolario, la teoría de la compensación llega a dar cuenta del renacer de los conflictos nacionalistas en un mundo supertecnificado. La alienación tecnológica de la modernidad exige entregarse, a veces fanáticamente, a la busca y defensa de alguna raíz, de alguna tierra en la que estar enraizado. Obliga a tener un pasado, aunque sea inventándolo. $Y$ a identificarse con él. Tal sería la política de la llamada postmodernidad.

\section{El turista y el ángel de Paul Klee}

El hombre moderno mira al pasado con cierta condescendencia. Ya hemos visto que lo mira como turista, viaja por él. No en vano, "el pasado es un país extranjeron. Goza especialmente de las novelas históricas, de las piedras antiguas, y también de las amontonadas como ruinas. Se demora en ellas sin contemplarlas demasiado, sin embargo. Se diría, además, que encuentra en ellas más una melancólica serenidad, como la de las pinturas románticas, que esa desolación de que hablaba Hegel al comprobar que uen la historia caminamos entre las ruinas de lo egregio" 7 . Por otro lado, el ángel de Paul Klee que describe Benjamin ${ }^{8}$, "parece como si estuviera a punto de alejarse de algo hacia lo que mira fijamente. Los ojos desorbitados, la boca abierta, las alas tensas", es el ángel de la historia. Tiene la vista vuelta hacia el pasado, un paraíso convertido en catástrofe, que arroja ruinas a sus pies. El montón de ruinas crece hasta el cielo, y él quisiera "despertar a los muertos y recomponer lo despedazado." Pero un huracán, «atrapado en sus alas», lo empuja lejos del paraíso destruido, hacia el futuro que queda a sus espaldas. "Lo que nosotros llamamos progreso es ese huracán». El turista conffa en el progreso para restaurar las ruinas. Espera que las ruinas preservadas le salven del progreso. Espera que el avance del conocimiento científico en todos los campos le ayude a preservar e incluso restaurar

6 O.c., pág. 93.

7 Lecciones de Filosofia de la Historia Universah Madrid, Alianza, 1997, pág. 50.

8 O.c. pág. 146. En la célebre tesis VI sobre Filosofia de la historia. 
todas las ruinas, se las presente tal y como eran ${ }^{9}$. En el pasado, el ángel de Paul Klee ve "una pura catástrofe». El hombre moderno ha convertido la catástrofe en parque de atracciones. En el mismo viaje, digiere Buchenwald, el Museo del Prado, un parque natural. Ningún huracán le aleja del pasado. Es él quien, para asegurarse el confort espiritual, se lleva el pasado al futuro. El pasado preservado. Un pasado cargado de tradiciones que necesita para seguir respirando. Tiende a conformarse con el pasado. Triunfalista a pesar de su presente, ignora que "hay una tradición que es catástrofe" ${ }^{10}$. Una catástrofe oculta. Que plantea una tarea irresuelta: "Hay que intentar en toda época ganarle la tradición al conformismo que está a punto de dominarla" ". La tradición, por otro lado, es un "acontecer de cada presente». El verdadero acontecer rompe todo conformismo y condescendencia. Pero no se trata simplemente de una crítica.

\section{Los usos de la historia}

Se trata también de una vieja pregunta nietzscheana, planteada en la Segunda Intempestiva. ¿Cúanta historia necesita la vida, y qué clase de historia? Pero ninguna de las tres clases de historia necesarias que distingue Nietzsche parece ser la del turista, ni, al menos, por ahora, la del ángel de Benjamin. La historia monumental la los activos y esforzados (die tätigen und strebenden), la del héroe que, sumido en un gran combate, necesita modelos, maestros, grandes figuras que le consuelen y le animen, podría ser, en cierto modo, la vieja historia magistra vitae de los antiguos. La noción moderna de historia, con su idea de progreso, disuelve cualquier monumento en tanto que lo preserva. Lo grande del pasado no debe permanecer eterno para ser imitado, tanto más cuanto que el pasado es ruina. Si el riesgo de un exceso de monumentalismo era "que los muertos entierran a los vivos" ${ }^{12}$, el presente del turista expone simplemente las tumbas de los muertos. El ángel de Benjamin, en cambio, vuela gracias a ellas, al huracán que despiden. Tampoco pertenece al turista, a pesar de las apariencias, la historia del anticuario, la del que "conserva y honra». Cierto es que la conciencia histórica contemporánea, como el anticuario de Nietzsche, «vuelve la vista hacia atrás con amor

9 O tal y como los expertos contemporáneos creen que deben presentarse. Las discusines sobre esto no han terminado aún.

10 En «Theorie des Fortschritts”, Das Passagen-Werk, Suhrkamp, Fráncfort, 1983, pág. 591.

11 O.c., pág. 144.

12 NieTzSCHE, o.c., pág. 262. 
y lealtad, hacia el lugar de donde viene, donde ha llegado a ser el que es; y por esta piedad le rinde, de algún modo, el agradecimiento de su existencia" " ${ }^{13}$, y es cierto que unas raíces románticas de las que aun hablaremos le hacen buscar en el pasado el nido patrio de su existencia, y que para ella, "el hecho de que algo haya quedado antiguo conlleva el imperativo de que sea inmortal" ${ }^{14}$. Pero destruye tanto como conserva, y aunque, como el anticuario, acabe a veces "más momificando que conservando", no se puede decir de ella que "mate el devenir" o quede fija en el pasado, como Nietzsche temía que ocurriera en este tipo de historia. Tanto menos el ángel de Benjamin, presa del huracán del progreso. Finalmente, la historia critica. Es la del que "sufre y necesita liberarse", la de quien tiene la fuerza de romper con el pasado, entrar en él a cuchillo y "reconocer que una casta, un privilegio, o una dinastía merecen venirse abajom. A primera vista, la conciencia de nuestro turista podría jactarse de ello: se originó en un corte radical con la tradición, durante el siglo XVIII, en una negación de todo lo pasado para proyectarse al futuro. Pero, en lugar de dotarse de un nuevo pasado de auténtico valor, en lugar de recrear sus raices desde las ramas, se sumerge en una espuria labor de anticuario, suspira por el pasado que ha destruido para poder soportar el futuro hacia el que vuela. Aquel para quien el pasado es un contrapeso terapéutico, no puede ser crítico con él. ¿Y el ángel de Benjamin? No busca romper con el pasado, sino que de la obligada ruptura que nace de éste, de su ruina, vuela hacia una meta que vislumbra como nostalgia.

Y sin embargo, los tres modos de usar la historia, cuyo equilibrio, a juicio de Nietzsche, es decisivo para una vida sana, están igualmente arraigados en la condición histórica de la existencia. En tanto que ser temporal, y por tanto histórico, la historia del hombre no puede ser sino "monumental", "anticuaria" y "crítica" a la vez ${ }^{15}$.

Pero ni la Historia del turista lo es del todo, ni la de su contraparte, el ángel de Benjamin, tampoco. Parece, por ello, pertinente plantearse el juego de relaciones entre pasado, historia y futuro que tiene lugar aqui. Pues, de algún modo, la triple articulación nietzscheana debe encontrar aquí su consideración. Nietzsche lanzó estas reflexiones en el entorno del abrumador crecimiento del

13 Ib. 265.

14 Ib. 269 Véase en The past is a foreign country, pág. 36, sobre la fundación del National Heritage en el Reino Unido y las disputas a las que va unido.

15 Sein und Zeit, 396. Si bien Heidegger esboza esta triple coimplicación desde un predomino del futuro que au discutiremos luego. 
saber histórico en la Alemania de su época, que le hacía reclamar algunas dosis de olvido que, como aire fresco, aliviaran de nuevo la vida. "Pues todo lo grande se ha hecho en una atmósfera ahistórica (unhistorisch)". El turista, en cambio, combina la asfixia del saber histórico con la mayor capacidad para el olvido que ha conocido, irónicamente, la historia. Lo que el ángel recuerda está por ver todavía.

\section{Los orígenes de la historia}

Será preciso detenerse por un momento en el viejo tópico de la invención moderna de la historia, en la medida en que sólo dentro de él tiene lugar la experiencia del turista y la del ángel de Benjamin. Antes de la segunda mitad del siglo XVIII, nos enseña Koselleck ${ }^{16}$, nadie hubiera dicho algo así como "Estudio historia". La historia siempre lo era de algo: del imperio, de las doctrinas teológicas, de Francia.... Sólo a partir de entonces se empieza a hablar de una historia sin más ${ }^{17}$, un colectivo singular cuyo objeto y sujeto es la humanidad misma, y que da lugar a una "Historia Universal», donde quedan englobadas y recogidas todas las historias particulares, las de los pueblos, las ideas, las costumbres, la técnica. A partir de Napoleón, aparece incluso la hoy ya manida expresión de "hacer historia»: antes, las historias se investigaban, se contaban, o se escribían. Esta Historia Universal, en cambio, es directamente hecha, producida por sus mismos sujetos, es obra del hombre. Este colectivo singular de la historia apareció con cuatro rasgos peculiares que habían ido perfilándose con la Edad Moderna y denotan el cambio de experiencia que ésta supone, y la disolución del viejo topos de historia magistra vitae, que habia gobernado la reflexión histórica desde la Edad Antigua.

El primero de tales rasgos es la singularización de la historia, la consideración de ésta como algo único e irrepetible, que se da una sóla vez ${ }^{18}$, con lo que los acontecimientos del pasado pierden su valor paradigmático. No hay ya un pasado eterno dado desde siempre, que solo puede repetirse infinitas veces. En

16 Vergangene Zukunft, Suhrkamp, Fránfort, 1995 pág. 263. Koselleck da incluso la fecha exacta: antes de 1780 .

17 Es, por lo demás, también la época en que, de las «libertades», resulta la Libertad, de las «justicias", la Justicia, de los progresos, el progreso, de las revoluciones, la Revolución.

18 O.c., ib., págs. 48-62. 
lugar de ello, y este es el segundo rasgo, la historia se hace factible, producible; son los hombres mismos quienes la hacen $y$, hasta cierto punto, disponen de ella. La impulsan adelante, la planifican incluso, aunque ocasionalmente sufran sus reveses. Pues, por el hecho mismo de ser factible la historia, los hombres pueden verse sobrepasados por su propia obra. La experiencia de la historia es la experiencia de un poder superior. La historia que se hace, he aquí el tercer rasgo, queda por encima de los hombres individuales y de los pueblos que la impulsan. Finalmente, la historia es periodizable, clasificable en tiempos esencialmente diferentes entre sí. El cuarto rasgo decisivo de la historia es el establecimiento de un tiempo histórico específico, distinto del cronológico, que permite la distinción en épocas; esta distinción, a su vez, se hace posible desde el momento en que los hombres se consideran situados en un tiempo nuevo (Neuzeit), nunca visto antes, la Edad Moderna, definida respecto a una Edad Antigua, ya pasada para siempre, y una Edad Media u obscura interpuesta.

A partir de ahora, los acontecimientos, los eventos, dejan de darse aisladamente, y pasan a formar parte de un conjunto en el que quedan englobados. «El historiador digno de este nombre tiene que presentar cada evento (Begebenheit) como parte de un todo, o lo que es lo mismo, tiene que presentar en cada evento la forma de la historia en general» ${ }^{19}$. Es el conjunto, ese suceso único que es la historia, lo que debe dar sentido a cada uno de los acontecimientos del pasado. Estos no son ya modelos a imitar; son pasos en el curso de la historia, y en los que se puede rastrear, por ejemplo, la posibilidad del progreso. Con la historia aparece, a la vez, la filosofía de la historia: esa curiosa mezcla de política, profecía y racionalidad que sustituye a las antiguas adivinaciones ${ }^{20}$.

Aunque la filosofla de la historia ha perdido crédito desde sus inicios hasta hoy, no cabe duda de que el turista con el que abordamos la conciencia histórica contemporánea tiene visión filosófica mínima del todo en el que encajan los acontecimientos, y por ende, su propia reflexión sobre la historia misma. Esta filosofia de la historia es un producto combinado de todas las que ha habido en los últimos doscientos años, pero podemos fijarnos en dos extremos, dentro de los cuales se sitúa su pensamiento sobre la historia.

El primero de ellos es la forma más depurada que se ha propuesto de filosofía de la historia universal, vertebrada por el concepto de progreso. La

19 HuMbOLDT, «Sobre la tarea del historiadorm. Cita tomada de KOSELlECK, o.c., pág. 54.

20 KOSELleCK, o.c., págs. 33, 56. 
encontramos en un Schiller "atracado de kantismo" "21, en la célebre "¿Qué significa y con qué fin se estudia Historia Universal?" 22. Desde luego, se encuentran ahí todos los tópicos de la filosofía ilustrada de la historia que la crítica contemporánea insiste en demoler. Pero precisamente esa insistencia permite pensar que tales tópicos deben de tener un asiento firme en el pensamiento; consciente o inconsciente, sobre la historia, y por ende, en la sensibilidad histórica de nuestro turista. También éste ve las épocas pasadas como uestadios que ha atravesado el ser humano", edades que "se han esforzado, - sin saberlo o pretenderlo- por conducir a nuestro siglo", de modo que "los períodos más diferentes de la humanidad contribuyen a nuestra cultura, como las partes más dispersas a nuestro lujo». También él, como la mente filosófica que bosqueja la Historia Universal schilleriana, sabe destacar, de entre los acontecimientos del pasado, "aquellos que han ejercido una influencia esencial, irrevocable y fácil de discernir en la configuración actual del mundo y en la generación que vive actualmente». Quizá no hable ya, como Kant, de un plan secreto de la naturaleza que impulse el progreso, ni que éste sea inevitable; pero sí está imbuido de la superioridad moral del progreso, y de que ésta queda transferida a él en la medida en que sea hijo suyo, resultado de la historia. No en vano, utiliza siempre el "progreso" como argumento en la discusión política. Por eso, si contempla los monumentos con esa mezcla de veneración y condescendencia es porque, mentalmente, dispone también, como Schiller, de "la historia que permanece inmóvil y expuesta a toda contemplación, una ciudadana inmortal de todas las naciones y todos los tiempos».

El otro extremo en la filosofla de la historia es, en realidad, la otra cara de la medalla ${ }^{23}$. Si la historia es única y evoluciona de una época a otra, cada una de las épocas son por principio diferentes entre sí, e irrepetibles. El ayer del hoy, el hoy del mañana. El tiempo histórico específico que permite periodizar la historia le da, a su vez, una cualidad autónoma a cada uno de los períodos. Y ya sólo hay un paso de ahí a considerar cada uno de ellos, no como etapas de tránsito hacia el presente, medios para llegar a la humanidad de nuestros días — con los problemas morales que esa consideración implica ${ }^{24}$ _, sino

21 Según DuQUe, El sitio de la Historia, Akal, Madrid, 1995, pág. 57.

22 En SCHILLER, Escritos de Filosofla de la Historia, Ediciones de la Universidad de Murcia, Murcia, 1991, págs. 1-18

23 Así, la caracterización del historicismo por KOSELLECK, o.c., 192.

24 Planteados por el propio Kant en su tercera tesis de Idea de una histori universal en sentido cosmopolita. ¿Son los hombres de otras épocas únicamente medios para llegar a nosotros? 
como épocas "todas inmediatas a Dios" ${ }^{25}$. No hay razón para considerar a una época mejor que otra. Por supuesto, esta postura del historicismo tiene sus rafces lejanas en la crítica de la Ilustración por Herder, quien reprochaba a la "fría filosofia» de la Ilustración el arrogarse el derecho de valorar y enjuiciar las épocas pasadas; pues nada es más estúpido "que arrancar la virtud de los egipcios, del tiempo y la Edad infantil del espíritu humano, para medirla con los patrones de otro tiempo" ${ }^{26}$. Pero el padre más inmediato del historicismo, tal como lo asume nuestro turista, es un cierto postulado de objetividad según lo plantea el positivismo del siglo XIX, justamente desde la fe en el progreso y el descrédito de los prejuicios ${ }^{27}$. Puesto que, para conocer las cosas, hay que estudiarlas tal y como se nos dan y se constituyen objetivamente, evitando cualquier injerencia nuestra, o de la razón, o de nuestros prejuicios, también las épocas del pasado tendrán que ser estudiadas en su autonomía, de modo que "si ustedes quieren revivir una época, deben olvidar todo lo que saben que ha pasado después de ella» ${ }^{28}$. Es la ilusión romántica de saltar por encima del abismo del tiempo para acercarse a las cosas tal como ellas eran, en su pureza originaria, y mostrarlas, según pedía Ranke, "wie es eigentlich gewesen ist" ${ }^{29}$. Esta ilusión del observador neutral, situado fuera del tiempo, que se acerca a todas las épocas, ha sido suficientemente desmantelada desde entonces ${ }^{30}$. Pero aun sigue activa en el imaginario histórico contemporáneo, que, no en vano, ha hecho de la máquina del tiempo uno de sus argumentos de ciencia-ficción favoritos. Sólo así se explica que cada pasado parezca adquirir un valor por sí mismo, para convertirse en una especie de "época dorada" que se desea ${ }^{31}$, se venera, o cuyos restos se pretende conservar tal como "efectivamente eran", ya se trate de un palacio renacentista o de la exacta interpretación de una partitura tal como Bach la hubiera tocado. El moderno que se lleva al futuro el contrapeso del pasado, quiere creerlo intacto, igual que fue en su día.

25 Así en la formulación de RANKE, Über die Epochen der Geschichte. Cita tomada de KOSELLECK, o.c., pág. 174.

26 Auch eine Philosophie der Geschichte Werke, X? pág. 490.

27 Y, dicho sea de paso, a imitación de las triunfantes ciencias naturales.

28 FUSTEL DE COULANGES, citado por Benjamin en Passagen-Werk, 0.c. 590, y en Über den Begriff der Geschichte, 144.

Cita tomada de KOSELLECK, o.c. 55.

30 Baste mencionar los ańlisis de GADAMER en Verdad y metodo sobre el problema de la conciencia histórica.

31 Véase LOWENTHuL, o.c., 23-25, como crecen a lo largo del siglo XIX y XX las mitologias de esas epocas doradas, aunque, los distintos sujetos que sokaban con trasladarse a ellas buscan, sin embargo, todos lo mismo. 


\section{6. ¿Cómo puede haber épocas?}

Uno de los cuatro rasgos con los que nace la historia es su periodización, la conciencia de que existe un tiempo histórico específico distinto de los ciclos naturales, de modo que «el tiempo de los hombres es distinto del tiempo de la materia” ${ }^{32}$. Anteriormente, cuando no había la historia (ni la Historia), sino historias, los acontecimientos históricos se determinaban según dos categorían naturales del tiempo, como eran el curso de las estrellas en el firmamento, o la sucesión hereditaria de príncipes y dinastías. Pero ahora se cuentan las épocas - Barroco, Renacimiento, Edad Media - y los siglos. Ya hemos visto que dentro de ellas encasilla el turista, con una etiqueta, los restos del pasado conservado con los que se encuentra. Se empieza a hablar de un genius saeculi ${ }^{33}$, cada una de esas épocas o siglos tiene un significado y un espiritu propio. En cierto modo, "escribir historia significa darle su fisionomía a los números de los

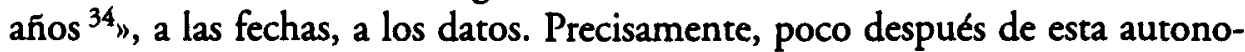
mización del tiempo histórico se acunaría en Alemania un término que ha gozado de rara fortuna internacionalmente: el Zeitgeist ${ }^{35}$, el espíritu del tiempo, el que es propio de cada época. Es el mismo Kant quien se hace portavoz de la nueva noción de tiempo histórico al rechazar el antiguo cómputo del tiempo, «como si no tuviera la cronologia que regirse por la historia, sino, a la inversa, la historia por la cronologían ${ }^{36}$.

Sin embargo, el progreso que acompaña el nacimiento de la noción de historia no deja de apoyarse, por decirlo con Heidegger, en una "concepción vulgar del tiempo", por la que lo pasado, la provenencia, todo lo que existe, parece tener lugar "en el tiempo", como si éste fuera un receptáculo distinto de lo que entra en el. Benjamin reprocha a esos ilustrados ejemplares que son los socialdemócratas imaginarse un progreso de la humanidad infinito, inevitable, que no es posible diferenciar de un proceso que tiene lugar en un «tiempo homogéneo y vacion " ${ }^{37}$. Una especie de tiempo absoluto, newtoniano, que acoge

32 LLEDO Lenguaje e historia, Taurus, Madrid, 1997, pág. 78.

KOSELLECK, o.c. 322.

34 Benjamin, PASSAGEN-WERK, 595.

35 KosELLECK, 337. Junto a otros muchos compuestos con la palabra Zeit. El tiempo es calificado.

36 Kant, en la Antropología. Cita tomada de KOSSELECK, o.c., pág. 58.

37 Über den Begriff der Geschichte, 0.c.. pág. 150. 
los acontecimientos como algo externo a ellos. Intuitivamente, el turista parece asignar sus etiquetas con la misma ingenuidad con que se van midiendo los tiempos de paso en el recorrido de un deportista. De este modo, el concepto de época, como un tiempo pleno que experimentan los hombres que en él viven, queda vacío de contenido. Como si la humanidad fuera pasando por los siglos XVI, XVI, XVIII igual que un automóvil pasa por los "puntos kilométricos" 100, 150 o 200. Cuando el siglo XVI es algo que le pasa a la humanidad, dándole un determinado sentido que no es diferente del tiempo en el que está. El enraizamiento del hombre en la temporalidad, por volver a decirlo heideggerianamente, hace que los hombres del siglo XVI no sean otra cosa que el siglo XVI mismo; por eso son históricos. Y ello es lo que hace insatisfactoria la clasificación de la historia universal en épocas transitorias, tal como aparece en Schiller ${ }^{38}$; pues, entonces, toda la historia universal queda reducida a un cuadro sinóptico, tan inmóvil y atemporal como la gráfica donde se representa el desplazamiento de un móvil. El tiempo queda congelado en el espacio, y la historia, según veíamos, uinmóvil y expuesta a la contemplación, una ciudadana inmortal de todos los tiempos" ${ }^{39}$.

Herder, contemporáneo de Kant, ha captado mucho más profundamente esa autonomía del tiempo histórico. No es sólo que «toda época tiene su centro de felicidad dentro de sí, como toda esfera tiene su centro de gravedad" ${ }^{40}$, por lo que resulta "estúpido" juzgar a un tiempo desde otro, sino que "todas las cosas sometidas al cambio llevan consigo la medida de su propio tiempo; y esta medida sigue existiendo aunque no hubiera ninguna otra. Hay por ello en el Universo (puede uno atreverse a decirlo), un sinnúmero de tiempos a un tiempo" "1. Y cada uno de esos tiempos "no simultáneamente sinmultáneos" debe ser contemplado en su autonomía. Es evidente que a partir de aquí puede cobrar impulso todo el historicismo y la propuesta de Fustel de Coulanges. Las épocas, los mundos históricos, deben ser considerados en si mismos. No hay un tiempo exterior al reloj de la historia, desde el que medir si las épocas de ésta van con retraso o con adelanto. El tiempo lo va marcando el reloj mismo, porque no es distinto de él ${ }^{42}$.

\footnotetext{
38 O en Voltaire y cualquiera de los ilustrados.

39 O.c., pág. 17.

40 Auch eine Philosopbie... en loc. cit., pág. 509.

41 Metakritik der reinen Vernunft, Berlin, 1955, pág. 68. Cita tomada de KOSELLECK, o.c., pág. 10.

42 Lo cual tampoco quiere decir que siempre vaya ka tiempon, que siempre sea justo. Tal sería la perspectiva relativista. Pero en este problema no podemos entrar aquí.
} 
De hecho, la inflación del concepto de época llegó con el historicismo y su necesidad de hacerse con individualidades históricas con las que tratar en el curso de la historia ${ }^{43}$. Aparte de su uso en la filosoffa escéptica, la epoché designaba antiguamente en astrología la coincidencia de dos cuerpos celestes en su movimiento relativo: una constelación, como un punto detenido en el tiempo, desde el cual era posible calcular cronologías ${ }^{44}$. Para la historiografia de la Edad Moderna, la época empieza por designar un punto: el nacimiento de Cristo, la creación del mundo, la fundación de Roma. Pero, con la Ilustración, la Revolución, y la idea de progreso, pasa ya a ser un segmento de tiempo que articula todo el curso temporal y queda definido por la "prevalencia de un determinado estado de cosas". La historia universal se clasifica a partir de ahora en épocas, segmentos temporales. Estos se constituyen como unidades individualizadas de acontecimientos y efectos conectados entre ellos. Y el estado, la configuración de los personajes y los sucesos, se vuelve más importante que la acción individual. Los grandes acontecimientos históricos, por otro lado, serán los que produzcan un nuevo estado de cosas, den lugar a una nueva época, sean epochemachend ${ }^{45}$. Y es a estas unidades temporales a las que debe dirigirse fielmente el estudio histórico, como mónadas independientes, cada una con su propia medida, cada una con su propio horizonte con iguales derechos a la historia. Ningún tiempo ha sido medio, todos son siempre un fin, y la historia es el paso de Dios a través de ellos.

Sin embargo, la misma fidelidad al pasado que alza las épocas como unidades independientes tiende igualmente a disolverlas. A poca diligencia que aplique el conocimiento histórico, un cúmulo de observaciones y reflexiones comienza a mostrar la acción soterrada de los tiempos anteriores sobre los posteriores; y la fractura entre épocas queda sustituida por una continuidad oculta, donde el pasado hace valer su inercia sobre cualquier conciencia de ruptura o voluntad de un comienzo nuevo. Nada se ha considerado a sí mismo tan innovador como la Edad Moderna; pero un poco de laboriosa investigación historiográfica ha bastado para mostrar cuánto de medieval seguía habiendo en Descartes, en Bacon, o en Galileo, a pesar de la conciencia inaugural que ellos tenían ${ }^{46}$. La propia historia deshace, pues, las rupturas que ella misma necesita III, 597.

43 Blumenberg, Die Legitimität der Neuzeit, Suhrkamp, Stuttgart, 1996, pág. 531.

44 Seguimos aquí a Manfred Riedel, en RITTER, Historisches Wörterbuch der Philosophie
45 BLUMENBERG, o.c., 533-34
46 Ib. 
para estudiar. No es sólo que haya, como veĺa Herder, innumerables tiempos a un tiempo, sino que cada uno de esos tiempos, medida de épocas autónomas, está grávido a su vez de otros tiempos anteriores, de las épocas de las que proviene. El pasado sigue pesando aunque se lo olvide, aunque se tenga voluntad de olvidarlo. La inercia del pasado parece imponer una continuidad que tiende a disolver las rupturas. Esas mónadas individuales que son las épocas se articulan entre sí, y los innumerables tiempos constituyen un entramado de sucesiones más o menos continuas en el que se da el tiempo, un tiempo que no es de ninguna época determinada y que permite pensar la historia, tal como la veía Novalis, en un "secreto encadenamiento de lo pasado y lo futuro" ${ }^{47}$. Por eso es tan dificil determinar el punto de diferenciación (cuando no de ruptura) en que una época se convierte en otra; y por ello nos admiramos de la audacia con la que un Goethe pudo decir, tras la batalla de Valmy, "a partir de aquí comienza una nueva época en la historia universal" ${ }^{48}$. Pues ni el historiador puede decir nunca con exactitud en qué momento la Edad Media se convierte en Renacimiento, o la Edad Antigua en Medievo; ni el habitante de una época puede decir con precisión cuándo y por qué está entrando en otra. Una de las primeras consecuencias de la irrupción de la historia a mediados del siglo XVIII ${ }^{49}$ es que el conocimiento de lo contemporáneo, de lo más reciente, se hace mucho más difícil. Por primera vez, se empieza a reclamar la perspectiva de la distancia temporal para conocer la verdad de los acontecimientos ${ }^{50}$. Hace falta un sentido especial para la medida del tiempo y la dialéctica de continuidad y discontinuidad de la historia. Llamémoslo sentido histórico.

\section{El sentido histórico}

Podría ser definido, en principio, como la capacidad, para captar la condición histórica de todas las cosas humanas, y tratar con ella. Esa condición que Dilthey resumía en su célebre «lo que el hombre sea es algo que sólo experimenta a través de la historian. Y tal condición se expresa, sin duda, como

47 Novalis Heinrich von Ofterdingen, en Werke in einem Band, Weimar, 1983, pág. 179.

48 Tomado de BLUMENBERG, 531.

49 KOSELECK, 332.

so Piénsese que, todavía para Herodoto, la historia sólo tenía valor si contaba con el testimonio de los testigos directos de los acontecimientos. 
mudanza y alteración. Ahora bien, los sentidos funcionan de un modo subconsciente, automático. El exceso de conciencia histórica, su sobreexcitación, tal como es propia del historicismo, denotan una cierta torpeza del sentido histórico, y con ello, una cierta desmaña para moverse en medio de las mudanzas de la historia. Es preciso percibir algo fijo para orientarse en medio de tales mudanzas. Así, al igual que el sentido del movimiento, por ejemplo, va ligado a la habilidad para mantener una cierta constante en medio del cambio, el sentido para lo histórico tiene que basarse igualmente en algún tipo de permanencia, en algo que se mantenga en medio del movimiento y le de figura a éste. Lo permanente ha sido visto de modos diversos. Herder, a quien no sin razón se ha atribuido un papel fundamental en el descubrimiento del sentido histórico ${ }^{51}$, lo veía en aquello que permite descubrir las "fuerzas del corazón humano en todos los tiempos y en todo acontecer» ${ }^{52}$, pues «el género humano tiene la suma de la humanidad en todos los tiempos, aunque en cada uno de modo diferente". Hay un "estado de persistencia" en la historia humana, y que corresponde a la cualidad humana misma, lo que él llamaba Humanität. El sentido histórico permite ver esa Humanität, esa esencia humana universal latente que desarrolla su fuerza sobre todos los tiempos y en todas las culturas, sin igualarlas por ello entre sí. Tampoco le faltaba sentido histórico a Hegel, para quien lo permanente sería la razón; y la labor del historiador pensante, elaborar una filosofia de la historia universal que ponga al descubierto «una obra íntima, silenciosa y secreta, en que se conserve la fuerza de todos los fenómenos» ${ }^{53}$, y que sería la obra de una razón única manifestándose. En la filosofia que hemos supuesto a nuestro turista, y que justifica como compensación su necesidad de pasado, tampoco falta una concepción del sentido histórico. Éste no es más que el arte de, sobreponiéndose a la vertiginosa aceleración del progreso, darse cuenta de la velocidad de envejecimiento y devolverle posibilidades a lo antiguo, es un sentido inercial capaz de ver "cuán pocas cosas han cambiado cuando todo cambiay ${ }^{54}$. El sentido histórico no se basa en la experiencia del cambio, sino en la de de sus límites: busca cuánto de nosotros hay en las historias y las épocas de las que nos alejamos, a fin de llevarlo a ese futuro desconocido y alienante. De ahí su necesidad de conservar.

51 GADAMER Herder und die Geschichtliche Welt, en Gesammelte Werke, 4, pág. 325.

52 Ib. 324.

53 Lecciones sobre Filosofia de la Historia Universal. Alianza Editorial, Madrid, 1997, pág. 52.

54 MARQUARD, o.c., pág. 93. 
Ahora bien, la distinción de las épocas como objetos históricos individuales que nos estábamos planteando más arriba, parece exigir más la diferencia que la continuidad, más el cambio que lo permanente. Lo contrario, pues, del sentido histórico. Necesitamos buscar y definir las cesuras. Conviene pensar, sin embargo, que cada época y cada cesura se mide desde un presente, y que es siempre un hoy quien comprende a un ayer. Entre uno y otro se debe dar también la permanencia que busca el sentido histórico. Se puede afirmar aun más radicalmente: únicamente existe el sentido histórico, y la condición histórica misma, porque hay algún tipo de comunidad entre el presente más familiar y el pasado más exótico, y por lo tanto una constancia en el tiempo. Sólo que esa comunidad, en contra de lo que pueda pensar el turista disfrazado de caballero medieval en un castillo restaurado, no consiste en alguna identidad alcanzada con un alma ajena. Subyace a tal pretensión la ilusión historicista de que, para conocer un objeto histórico, un personaje o un hecho, basta con dejarlos tal como son y transponerse en su situación exacta ${ }^{55}$. Para lo cual se necesita saltar por encima de los abismos y las cesuras del tiempo. Comprender, sin embargo, no consiste en una "misteriosa comunión de las almas", sino en una "comunidad de sentido" ${ }^{56}$. Y el sentido, lejos de ser un sólido objeto de posesión, es una fuerza que lanza a quien participa de él en una dirección determinada. De ahí que no se trate de "trasponerse en la disposición anímica" de los hombres de una época, sino de alcanzar la perspectiva bajo la cual alcanzaron sus opiniones y pudieron realizar lo que realizaron. Por eso, el historiador no puede limitarse a recoger datos y hechos, sino que tiene que hacerse cargo de todo el campo de experiencias y el horizonte de expectativas de aquellos a quienes estudia. A ese horizonte pertenece todo un cúmulo de perspectivas que se abrían como futuros posibles, deseados o temidos, ante los agentes históricos. Tales futuros pasados pertenecen al campo de lo histórico tanto o más que lo realmente acontecido ${ }^{57}$. Y, ya sea en el modo de catástrofes, frustraciones, realizaciones parciales $u$ olvidos, tienen que ser asumidos por quien se propone conocer el pasado. Conocer las épocas pasadas exige poder mirar en la misma dirección en las que ellas miraban.

55 Seguimos aquí la crítica de Gadamer a la conciencia histórica. Tal crítica la ejerce Gadamer en los nombres de Dilthey y Schleiermacher; como ha mostrado posteriormente, injustamente respecto a estos pensadores. Pero no por ello deja de atinar en lo que a la conciencia histórica se refiere.

56 GADAMER Wahrbeit und Methode, pág. 297. (traducción española pág. 362).

57 Tal es la tesis fundamental del libro de Koselleck. Sobre expectativas y experiencias, más abajo. 
Se requiere, pues, que la mirada del presente y la mirada del pasado coincidan. Ahora bien, al menos la mirada del presente es cada vez distinta, y cada época vuelve a reescribir la historia, como decía Goethe. Y también es distinta, cada vez, la mirada con la que el presente mira al pasado. En esto descansa el principio hermenéutico de la Wirkungsgeschichte o historia efectiva. La presunta objetividad a la que aspira el historicismo es imposible porque sólo nos acercamos al pasado llevando todo nuestro presente a cuestas, y este presente es, a su vez, en una medida que él mismo no puede abarcar totalmente, resultado de un proceso histórico, precipitado de pasados anteriores y distintos de aquel al que se acerca. La distancia temporal se encarga de ir produciendo presentes, $y$ contribuye a las visiones que los presentes tengan de otros pasados. $Y$ el pasado, por su parte, nunca ha acabado de existir del todo, nunca llega a ser pretérito perfecto. Antes bien, existe únicamente en la continuación de la diversidad de sus efectos sobre los posteriores presentes, y es también distinto cada vez. Hay un desplazamiento continuo de horizontes comunes entre cada presente y los pasados. El sentido histórico resulta ser el sentido de la propia determinación por la historia, del saber-se histórico ${ }^{58}$, y a la vez, el sentido de la continuidad efectiva del pasado que se hace historia. Lo que permanece, entonces, no es el pasado, ni alguna substancia invariable y resistente al tiempo, sino el continuado fusionarse las perspectivas de pasado y presente.

Nuestro buen turista puede muy bien, por caso, visitar Roma provisto de una gufa escrita por un viajero inglés en 1850 . No va necesariamente peor equipado que el poseedor de una guía más moderna, a pesar de la acumulación de conocimiento histórico que ha tenido lugar desde entonces. En cierto modo, incluso si se detiene ante unas ruinas inalteradas desde entonces, tiene una visión más rica y múltiple, pues contempla a la vez la Roma de 1850 -donde el respectivo presente inglés de entonces ha puesto todas sus experiencias, temores y esperanzas - y la Roma actualizada hacia finales del segundo milenio. El tiempo transcurrido ha trabajado sobre las dos épocas, y sobre Roma misma.

Las cesuras entre las épocas, pues, son puestas por un presente posterior que se dirige al pasado. No en vano, como hemos visto, las épocas históricas, entendidas de modo puramente inmanente, son creación de un tiempo que ha

58 Que es lo mismo que no saberse nunca del todo. "Ser histórico signfica no revelarse nunca plenamente en el sber de sí mismon; GADAMER, Wabrheit und Methode, pág. 307 (traducción espanola, 372). 
tenido la audacia de llamarse a sí mismo "nuevo" o «moderno", y que por ello, tiene todas las dificultades para definir sus propios límites. El afinamiento del sentido histórico plantea una tarea del uso del pasado, que consiste, sobre todo, en saberse condicionado, y por ello limitado, por el tiempo que transcurre desde él: por el peso del pasado sobre cada presente. El anticuario, el monumental y el crítico están, sobre todo, construyendo su propio presente. Por eso, nadie es un simple turista de la historia.

\section{La historia del ángel}

"Para que un momento de la actualidad sea alcanzado por el pasado, no debe existir ninguna continuidad entre ellos" 59 . Es preciso, por lo menos, que la distancia temporal haya podido ejercer su productividad dejando al pasado manifestarse, y ello implica realizarse en otros presentes ajenos. Pero, a diferencia de lo que acabamos de ver en el sentido histórico, lo que aquí parece romperse es la continuidad que se atribuye a la tradición hermenéutica. Frente a ella, Benjamin reclama que "se haga saltar el continuo de la historia", pues el sentido de ésta se desvela en las rupturas, en las fallas y accidentes: allí donde surge de pronto lo imprevisible ${ }^{60}$. Es en esas fallas donde han quedado los derrotados, los masacrados, los que no tienen nombre, en la memoria de los cuales encuentra sentido la construcción de la historia. Justo lo contrario de la tradición hermenéutica, que vendría más bien dictada por la «historia de los vencedores" ${ }^{61}$. Pero la disputa entre continuidad y discontinuidad es menos decisiva de lo que puede parecer a primera vista, sobre todo desde que ula actualidad es reconocida como la otra cara de la eternidad" ${ }^{62}$ : cada fragmento discontinuo en Benjamin puede recoger una totalidad no diferente a la que se intenta expresar en la línea continua.

La misma idea de mónada de que se sirve Benjamin para acercarse al kobjeto histórico" disuelve cualquier simple oposición continuo/discontinuo. En tanto que independiente e inextensa, la mónada abona la discontinuidad; pero

39 Benajmin, Passagen-Werk, 587.

60 Moses, Stephane, El angel de la historia, Madrid, Cátedra, 1997, pág. 98.

61 Ib., 130.

62 BeN]AMIN, Gesammelte Schriften IV, 2, 910. Tomamos prestada la cita de MoSES, o.c., pág. 124. 
la armonía prestablecida mantiene igualmente una suerte de continuidad entre todas la mónadas. Se hace saltar una época determinada fuera del transcurso homogéneo de la historia, una vida determinada fuera de una época, una obra determinada fuera de una vida: pero para que «toda la vida quede preservada y asumida en la obra, toda la época en la vida, y todo el conjunto del transcurso histórico en la época" ${ }^{63}$. También hemos visto con Herder-que fue, al fin y al cabo, quien llevó a la historia la noción de mónada- que cada época encierra en sí su propia medida y su propio tiempo, pero actualiza en ella ya a toda la humanidad.

El tiempo de la historia, ya lo hemos visto, no es la forma vacía externa de los acontecimientos. Está lleno de tiempos-ahora (Jetztzeiten), de presentes. Para la revolución francesa, la Roma antigua era un pasado cargado de presente $^{64}$. Por eso quería ser Roma otra vez, asumir sus expectativas y sus experiencias. Esta actitud es, desde luego, monumental en el más puro sentido nietzscheano, pero de un modo tal que el monumento cobra nueva actualidad en virtud del «salto del tigre» que dan los revolucionarios para atrapar el pasado, llevando a cuestas su todo su ahora. Y ello porque "sólo se puede captar el pasado desde una conciencia sobreaguda del momento presente» ${ }^{65}$. El encadenamiento de pasado y futuro no es lineal.

El pasado sólo se presenta "como un relámpago" ${ }^{66}$. La verdadera imagen del pasado pasa en un vuelo, se desliza fugazmente ante nosotros, imposible de retener. Lo pasado es siempre lo otro, lo que no se puede apresar. Por eso no puede ser objeto de conocimiento objetivo, ni simple objeto de anticuario. (Aunque éste es necesario por el aura que lo envuelve; pero el aura es kla aparición única de una lejanía, como la de las estrellas fugaces ${ }^{67}$ ) Por eso no es posible identificarse con el pasado ni transponerse sin más en él. No puede haber una comunión de almas, sino una comunidad de sentido compartido. Pero el sentido se señala en un fulgor; el fulgor de una imagen "donde lo sido converge fulgentemente con el ahora en una constelación" ${ }^{68}$. Constelación

\footnotetext{
63 Uber den Begriff, en loc. cit. pág. 152. Es la tesis XVII.

64 Ib., pág. 150. Es la tesis XIV.

65 El dngel de la historia, pag. $128 \mathrm{cf}$. GADAMER, EN Verdad y método: "para acercarse al pasado, hay que estar viendo también el momento presentex. pág. 310.

66 BENKAMIN Über den Begriff... loc. cit., pág. 143. Tesis V.

67 MOSES, o.c., pág. 96.

68 Passagen-Werk, 576.
} 
era, originalmente, una época. En ella ocurre una detención del discurrir del tiempo. El presente cumple entonces su obligación de "reconocerse en un pasadon, y salvarlo así en un nuevo ahora. Esto ocurre como un despertar: esa conciencia entre el sueño y la vela donde da comienzo toda narración. La de Proust, que inicia la recuperación del tiempo perdido en el despertar que recuerda la lectura (por cierto, de un libro de historia) antes de dormir. Es el ahora de la Erkennbarkeit, la posibilidad de reconocer(-se). "Toda exposición histórica debe comenzar con el despertan ${ }^{69}$. Esa es la discontinuidad propiamente dicha ${ }^{70}$. También la de una comprensión súbita, un «de repente» en el que algo súbitamente cristaliza. La continuidad de la tradición sólo se realiza en la discontinuidad, la Plötzlichkeit de su reconocimiento. El conformismo queda entonces sacudido y es posible esa suerte de comienzo absoluto que corresponde a toda época histórica ${ }^{71}$. Puede ser Valmy, 1789, un momento determinado del Renacimiento, 1917. El ahora se llena de pronto de todo el tiempo, como un palimpsesto donde la escritura oculta se hace de repente visible y un futuro se abre: «la historia es similar a un texto en el que el pasado ha depositado imágenes como sobre una placa sensible a la luz. Sólo el futuro dispone de reactivos lo bastante poderosos como para hacer aparecer esta imagen en todos sus detalles" ${ }^{72}$. A ese momento le llama Benjamin la Redención, la Er-lösung: un desatarse del tiempo en el que la acción comienza. El pasado es liberado, transformado, y el huracán de la catástrofe impulsa al ángel hacia adelante.

\section{El peso de pasado y la ligereza de la historia.}

«Sblo para la humanidad redimida se ha vuelto el pasado citable en todos y cada uno de sus momentos" ${ }^{73}$. Sólo en un final mesiánico de la historia, cuando el tiempo se ha desatado, puede un cronista relatar todos los acontecimientos,

69 Ib. 580.

70 El motivo de la discontinuidad ocupa, frente a lo que creen muchas interpretaciones, un lugar central en la hermenéutica de Gadamer. Cf. "Geschichtlichkeit und Wabrheit", en Gesammelte Werke 10, 256; asi como "Die Kontinuität der Geschichte und der Augenblick der Existenz» en Gesammelte Werke 2, págs.13-146.

71 MOSES, o.c., pág. 150.

72 BENJAMIN GS I, 31238.

73 Benjamin, Öber den Begriff... en loc. cit., pág. 143. Tesis V. 
sin distinguir los grandes de los pequeños, de modo que nada quede perdido para la historia. Hasta entonces, para Benjamin, la historia registra sólo pérdidas. Hay un pasado olvidado y reprimido, la lectura de cuya huella es precisamente la tarea del presente. El pasado ha quedado siempre imperfecto, no ha acabado de ser, de modo que es revivido y reactualizado en las interpretaciones de la posteridad. En este sentido, la historia universal es, desde luego, como quería Hegel, el juicio universal; o bien, como dice Benjamin siguiendo una sugerencia de Kafka, cada día es ya el día del Juicio, el Juicio final está siendo en todos los momentos. Pues el final de los tiempos puede entrar "como un ladrón", en cualquier momento, $\mathrm{y}$ "tal y como haya encontrado a cada uno, así será juzgado» ${ }^{74}$. Pero, a diferencia de la Redención, donde se dispondría ya del pasado en su totalidad, cada presente, cada momento del tiempo, supone un juicio sólo usobre algunos momentos que le precedieron" ${ }^{75}$. Sigue habiendo un pasado oprimido $o$, cuando menos, velado.

Ello ocurre porque cada presente dispone además de un futuro, está instalado en un campo de experiencias y en un horizonte de expectativas. Desde la perspectiva de Benjamin que hemos seguido hasta aquí, el futuro es - secretamente, pues nadie lo adivinaría sin más en el horizonte de expectativastodo el pasado que queda por desvelar. No se olvide que el ángel de la historia avanza de espaldas, mirando hacia atrás: las revoluciones deben hacerse en nombre de los caídos y derrotados del pasado; no, como se imaginan socialdemócratas e ilustrados, en nombre del futuro, de los nietos liberados ${ }^{76}$. Es decir, a pesar de Heidegger, el pasado tiene la primacía, y no el porvenir. "El primado del Zukunft en Ser y tiempo es sólo aparente desde el momento en que él implica, exige el primado de la Gewesenheit [...] que es, en su aspecto más profundo, el Zukunft de todo Zukunftr ${ }^{77}$. Y es que conocer el presente, aun con sus expectativas, no es más que "dejar reposar el pasado en nuestra conciencia, y verlo constituirse en el cauce de la historia que se aleja” ${ }^{78}$.

Es verdad que todo acontecer humano tiene lugar en un campo de experiencias y frente a un horizonte de expectativas. Son, éstas, dos categorías

74 MOSES o.c., pág. 131.

$75 \mathrm{Ib}$.

76 Úber den Begriff... o.c., pág. 149. Tesis XII

77 VITiello, Dialettica ed ermeneutica: Hegel e Heidegger, Guida, Nápoles 1979, pág. 34. Tomamos la cita prestada de Sansonetti, Il pensiero di Gadamer, Morcelliana, Brescia, 1988, pág. 201.

78 Lledó, o.c., pág. 94. 
históricas trascendentales, dos metacategorías que permiten fundamentar la posibilidad de la historia ${ }^{79}$. Pero no son simétricas: empezando por que la experiencia se designa como campo, y la expectativa como horizonte. La primera es pasado presente, la segunda, futuro traído a presencia. Pero la presencia del pasado es diferente a la presencia del futuro ${ }^{80}$. Sobre el campo de experiencias se está, y su particular orografía determina los movimientos del que camina, sin que sea posible librarse de las gravedad que lo ata a él. El horizonte es una línea inalcanzable de temor, esperanza, deseo, voluntad o preocupación, que se va desplazando con uno. La expectativa es siempre temprana, puede ser luego sobrepasada o quedarse corta; la experiencia ha llegado ya necesariamente, y siempre demasiado tarde ${ }^{81}$. El tiempo histórico, ese tiempo humano propio, se deriva de la tensión entre estos dos modos diferentes de ser ${ }^{82}$, entre lo que los hombres esperaban hacer y aquello por lo que habían pasado; pero es evidente que la cuerda del tiempo se tensa en el peso de la experiencia, del pasado consciente o inconscientemente elaborado.

No hay una transición continua del campo al horizonte, de la experiencia a la expectativa. De hecho, como ha mostrado Gadamer, la auténtica realización de toda experiencia consiste en tachar una expectativa ${ }^{83}$. La verdadera experiencia, la que no es una mera interrogación a la naturaleza, repetible siempre en determinadas circunstancias, sino un proceso único e irrepetible (y por eso es histórico, precisamente) por el que pasa el que lo hace ${ }^{84}$, la verdadera experiencia tiene siempre un resultado negativo: las cosas no son como creíamos que eran, no las habíamos visto del modo correcto. La experiencia es siempre la experiencia del límite, de la finitud. Las expectativas quedan corregidas, limitadas, tachadas, defraudadas; o cumplidas y acabadas. La experiencia va trazando los términos de lo que uno es, lo determina. Pone las lindes del campo.

79 KOSELLECK, o.c., pág. 354.

80 Ib. 356.

81 Goethe era drástico en este punto: «Para los individuos llega demasiado tarde, para los pueblos no existe nuncax. en KOSELLECK, o.c., pág. 355.

82 KOSELLECK, 357.

83 Cf. Wabrheit und Methode, págs. 352-367.

84 Recuérdese aquí la definición hegeliana de experiencia en la Fenomenologia del espiritu. "Ese movimiento dialéctico que lleva a cavo la conciencia, tanto en sí misma como en su saber, en tanto que en él brota ante ella el nuevo objeto verdadero" (pág. 58). 
Una vez establecida esta primacía de lo pasado, de lo sido, de lo hecho experiencia, sería inadecuado, sin embargo, apresurarse a identificar pasado, experiencia e historia, y considerar el pasado como un fondo latente y eterno que siempre se repite, desde el que nada nuevo es posible. No habría, entonces, historia ${ }^{85}$; ni siquiera experiencias irrepetibles. Pero las experiencias mismas, una vez hechas, cambian con el tiempo ${ }^{86}$, y el ángel de la historia, aunque con los ojos puestos en las ruinas del pasado, vuela - de espaldas- hacia el futuro, hacia lo nuevo.

La noción de progreso, despojada de la ingenuidad schilleriana, que en realidd negaba el tiempo histórico, no es "falsa», vacía. Puede ser definida, desde el esquema de Koselleck, como la diferencia creciente entre las experiencias y las expectativas. La edad moderna, la era del progreso, se caracteriza precisamente como aquella en que "las expectativas se alejan cada vez más de las experiencais hechas hasta entonces" ${ }^{87}$. La aceleración de la historia, que tanto vértigo produce en el hombre moderno (el turista) consiste en la anulación de todas las experiencias en nombre de expectativas absolutamente inéditas. El hombre moderno es el que se ha quedado despojado de experiencias, y es por eso el más pobre ${ }^{88}$. Por eso busca la compensación del anticuario. Sin embargo, y esto es lo que el turista no sabe, hay un progreso del pasado.

Desde luego, el pasado gravita sobre el presente en el modo de la experiencia. Es el campo de gravedad que determina lo que se es y prescribe los movimientos posibles. Pero el pasado no "ha sidom, no ha acabado de ser. Ya hemos visto que es siempre pasado imperfecto. No es un bloque estático, sino un continuo hacerse y constituirse en el presente que lo mira ${ }^{89}$ y salta sobre él con sus particulares expectativas: temores e ilusiones. El pasado sólo es parcialmente visible. "Sólo una parte de la historia es visible, mientras que la verdad de la historia se apoya justamente en esa parte invisible que se anade a todo hecho y que tiene que poner el historiador" ${ }^{90}$.

85 Tal serfa, según Duque, en $E l$ sitio de la historia, el caso griego.

86 KOSELLECK, o.c., 358. Lo cual, por lo demás, es sólo un fenómeno derivado de la historia efectiva.

87 Ib. 359.

88 Cf. Benjamin, Experiencia y pabreza. en Sprache und Geschichte, loc. cit., págs. 134-140. Por cierto que tamibén Benjamin definía el progreso como «la tensión entre un comienzo legendario y un final legendario", Passagen-Werk, pág. 596.

89 LLEDO, 0.c., 96.

9 HUMBOLDT, "La tarea del historiador», tomado de LlEDO, pág. 88. 
Su visibilidad es la del relámpago. "En los dominios de los que tratamos, sólo hay conocimiento en el modo del rayo. El texto es el largo trueno que sigue sonando después" ${ }^{91}$. Basta llamar a ese texto relato histórico, y tenemos una concepción de la historia que permite la apertura del pasado, la elaboración de la experiencia y la concepción del futuro. El peso del pasado se aligera en el relato de la historia. "Todas las penas pueden ser soportadas convirtiéndolas en una narración (story), o contando una narración acerca de ellas" ${ }^{92}$. El relato permite asumir la catástrofe del pasado y empezar a recomponer los fragmentos incompletos en los que se asoma.

La historia no es el pasado, sino su relato; «la consolidación en el lenguaje de todo aquello que, en cuanto real, desapareció en las fauces del tiempon ${ }^{93}$, y ésta es la definición mínima que se puede dar de ella, muy lejos de cualquier gran visión de la historia universal: «reproducción narrada de acontecimientos concretos en conexión" ${ }^{94}$. Nada más, pero tampoco nada menos. El pasado como tal, en «estado puro», es, ciertamente, lo más extraño y hostil. Determina el presente porque «somos lo que hemos sido", pero se aleja dejando a nuestros pies un montón creciente de ruinas. Es una pura pérdida. Pero el pasado en "estado puro" no se da. Lo que se da es su manifestación lingüistica en el relato, y es aquí donde se constituye la historia. Por el relato, el pasado deja de ser algo simplemente sido, un monstruo muerto colgado del ahora, para ser revivificado - sin exclusión del horror, por supuesto- como presente. El estrecho horizonte de su condición fragmentaria se amplia — tal era, como veíamos con Humboldt, la tarea del historiador-, el relámpago se extiende en el largo trueno de un texto que es la realidad misma, encuentra nuevas posibilidades que abren el futuro. Las ruinas de una ciudad bombardeada, por ejemplo, no son escombros, sino ruinas, porque tienen una historia.

La historia es necesaria para la vida porque, en ella, el pasado, cuyo efecto primero es paralizar la vida como un tejido muerto, queda salvado, alcanza una nueva perspectiva desde la que se puede anunciar un cambio. La transformación del mundo va unida a las enseñanzas de la historia. Esta no deja de ser, desde luego, la maestra de la vida; pero ya no porque haya que actuar según el

91 Passagen-Werk, 570.

92 Isak DINESEN, tomado de ARENDT, The Human Conditon, Chicago University Press, Chicago, 1989, pág. 175.

93 LLEDO, O.C.

94 BUBNER, Geschichspprozesse und Handlungsnormen, Suhrkamp, Fráncfort, 1984, pág. 11. 
modelo de los antepasados, sino porque el movimiento del relato histórico, de la narración de lo pasado, le enseña a uno el nuevo proyecto. Cada nueva decisión de lo que se va a ser supone un nuevo relato de lo que se ha sido. La fuerza de la vida requiere (Nietzsche) que la historia cambie, que lo ya conocido por todos se transforme en lo más inaudito. Que el pasado sea nuevo cada vez, sin dejar de ser pasado. No otra cosa puede ser el futuro.

Podría objetarse, en este punto, si no estamos dejando la historia al arbitrio del relato. Que no haya ya la Historia, sino historias diferentes en las que se elabora el pasado, parece hoy generalmente admitido ${ }^{95}$. Pero apenas hay un paso, se dirla, de ahí a la simple ficción. El imperativo de renovar el pasado se convierte en la licencia para inventarlo a capricho. Cuando la historia, como ya advertía Aristóteles, a diferencia de la poesía, sólo puede hablar de lo que ha sido, no de lo que podría ser. Y el propio Hegel advertía contra la confusión entre la historiografia fundamentada filosóficamente y la arbitrariedad de la novela, más interesada en enumerar detalles que en exponer un fin concreto racional ${ }^{96}$.

Pero la libertad de la narración - la historia es una decisión de contar el pasado - no exime de la responsabilidad frente al tema que la provoca. Se es libre de empezar a narrar, pero no se elige la materia con que se teje la trama. $\mathrm{Y}$ esa materia es el pasado, la catástrofe a los pies del ángel. El narrador es responsable frente al pasado que va a rememorar y salvar, que está interpretando. Y lo es tanto más cuanto que, al relatar el pasado, está constituyendo su presente, y todo lo que suceda a partir de él. No puede inventar una historia simplemente verosímil entre muchas - como una creación literaria más- porque el pasado realmente acontecido sigue pesando sobre el ahora, y sus fragmentos presentes se miden con cada nuevo relato. Puede haber infinidad de historias, pero el pasado es sólo uno, y de él, de su incompletud y sombras, de sus fracasos y fallas, se alimentas la narraciones: los largos ecos que siguen en la oscuridad al relámpago.

Suele distinguirse geschichte e historie, historia e historia, la historia acontecida realmente y el estudio científico de ella, la historiografia. Raza vez han

95 Baste mencionar dos perspectivas tan diferentes como VEYNE, Cómo se escribe la historia Alianza, madrid, 1984, y MARQUARD Universalgeschichte und Multiversalgeschichte, o.c., págs. 54-75.

96 Enzyklopädie $\$ 549$ A. 
coincidido. Duque dice que sólo en Herder en Hegel en Schelling. Nosotros no vamos a hacer la distinción. nos limitamos a la definición de historia de Bubner. la historia como relato de lo acontecido, y lo acontecido no es nada fuera del relato, el pasado sí, como gravedad que lo impulsa.

Dejamos de lado, por ahora, uno de los grandes problemas que plantea esta concepción. El relativismo de las épocas, y con él, el llamado problema de la conciencia histórica ${ }^{97}$. ¿Cómo es posible una razón universal y transhistórica, un tiempo humano, si cada época tiene la suya, igualmente legítima? Para el turista y para el ángel, que deben tener presente una imagen de la historia universal y de su propia historicidad, se plantea otro problema igualmente urgente.

97 GADAMER... 